\title{
Las mujeres que trabajaban en el área de cirugía del Hospital de las Cinco Llagas de Sevilla durante los siglos XVI al XVIII
}

\author{
Women working in the area of surgery at the Hospital of the Five Wounds \\ of Seville during the XVIth to XVIIIth century
}

\section{Las mujeres que trabajaban na área de cirugía do Hospital das Cinco Llagas de Sevilha durante os XVI XVI al XVIII}

\author{
Paula Ermila Rivasplata Varillas
}

\author{
Doctora en Europa, mundo mediterráneo y su difusión Atlántica. Doctora en Historia de América. \\ Universidad Pablo Olavide de Sevilla.Universidad Garcilaso de la Vega, Lima, Perú. \\ Cómo citar este artículo en edición digital: Rivasplata Varillas, P.E. (2018). Las mujeres que \\ trabajaban en el área de cirugía del Hospital de las Cinco Llagas de Sevilla durante los siglos XVI al \\ XVIII. Cultura de los Cuidados (Edición digital) 22,51. Recuperado de \\ <http://dx.doi.org/10.7184/cuid.2018.51.08> \\ Correspondencia: Departamento de Historia de América. Facultad de Geografía e Historia. \\ Universidad de Sevilla. C/Doña María de Padilla, s/n. \\ Correo electrónico: rivasplatavarillas@gmail.com. \\ Recibido: 09/05/2016; Aceptado: 12/10/2016
}

\section{RESUMEN}

El objetivo de este trabajo es conocer el área de cirugía del Hospital de las Cinco Llagas y el conjunto de personas que trabajaban en él, principalmente, las enfermeras de cirugía desde 1500 a 1808. En cuanto a la metodología, la primera fase del estudio comprendió una revisión archivística de fuentes primarias de diversos archivos y bibliográfica de fuentes secundarias para conocer el estado de la cuestión. Acto seguido se he procedido a interpretar y analizar los datos. Los resultados principales nos indican que esta área sólo recibía a mujeres heridas, que eran internadas en la sala de cirugía, llamada de San Juan, donde recibían el cuidado de la madre cirujana y sus doncellas quienes seguían las prescripciones dadas por el cirujano. Los instrumentos manejados en esta área eran las vendas, pinzas, jeringas, tijeras, cuchillos, sierras, hierros para cauterizar e incluso un instrumento ginecológico llamado el speculum matricis. Los resultados indican que este hospital podría ser un reflejo del desarrollo de la cirugía y de su personal en los hospitales castellanos de la Edad Moderna. Área que se encontraría bastante estructurada a fines del siglo XVI en el que destaca el binomio cirujano y enfermera de cirugía y el papel crucial que desempeño esta última en la atención del herido en un hospital castellano.

Palabras claves: cirugía, enfermeras de cirugía, cirujano, hospital, Sevilla, Edad Moderna

\section{ABSTRACT}

The objective of this work is to know the area of surgery of the Hospital of the Five Wounds and the group of people who worked there, mainly, the surgical nurses from 1500 to 1808 . Regarding the methodology, the first phase of the study included an archival review of primary sources of diverse archives and bibliographic of secondary sources to know the state of the question. Then, I proceeded to interpret and analyze the data. The main results indicate that this area only received wounded women, who were admitted to the surgery room, called San Juan, where they received the care of the surgeon mother and her maids who followed the 
prescriptions given by the surgeon. The instruments handled in this area were bandages, tweezers, syringes, scissors, knives, saws, irons to cauterize and even a gynecological instrument called the speculum matricis. The results indicate that this hospital could be a reflection of the development of the surgery and its personnel in the Castilian hospitals of the Modern Age. Area that would be quite structured at the end of the 16th century, in which the binomial surgeon and surgery nurse stand out and the crucial role that the latter plays in the care of the injured in a Spanish hospital.

Key words: surgery, surgery nurses, surgeon, hospital, Sevilla, Modern Age

\section{RESUMO}

O objetivo deste trabalho é conhecer a área de cirurgia do Hospital das Cinco Llagas e o conjunto de pessoas que trabalhou em ele, principalmente, as enfermeras de cirurgia desde 1500 a 1808. En cuanto à metodologia, a primeira fase do estudo incluída uma revisão arquivística de fontes primarias de diversos arquivos e bibliografia de fontes secundarias para conhecer o estado da questão. Acto seguiu se ele procedeu a interpretar e analizar os dados. Os resultados principais nos indican que esta área só recebemos as mulheres heridas, que eram internadas na sala de cirurgia, a chamada de San Juan, onde recebemos o cuidado da mãe cirujana e as criadas que seguiam as prescrições dadas pelo cirujano. Os instrumentos manejados em esta área eram as vendas, pinzas, jeringas, tijeras, cuchillos, sierras, hierros para cauterizar e inclusive um instrumento ginecológico chamado the speculum matricis. Os resultados indican que este hospital podem ser um reflexo do desenvolvimento da cirurgia e do pessoal nos hospitais da Edad Moderna. Área que é encontrada bastante estruturada a finais do século XVI em que se destaca o binômio cirujano e enfermagem de cirurgia e papel crucial que desempenhar esta última na atenção do herido em um hospital castellano.

Palabras claves: cirurgia, enfermeras de cirurgia, cirujano, hospital, Sevilla, Edad Moderna

\section{INTRODUCCIÓN}

El objetivo del estudio consiste en conocer las actividades desarrolladas en el área por las mujeres que trabajaban en un hospital castellano como fue el de las Cinco Llagas de Sevilla, por la madre cirujana y sus doncellas de dote, el cirujano y el barbero.

\section{METODOLOGÍA}

Las fuentes primarias utilizadas fueron las actas capitulares, los reglamentos, los inventarios, los libros de contabilidad y salarios que se encuentran en el Archivo de la Diputación Provincial de Sevilla. En cuanto a las fuentes bibliográficas para conocer el estado de la cuestión y estructurar el marco teórico se ha consultado diferentes bibliotecas como las de la Universidad del País Vasco, el Fondo Antiguo de la Universidad de Sevilla y la Biblioteca Colombina. Acto seguido se he procedido a interpretar y analizar los datos. Las siglas utilizadas en este trabajo son las siguientes: Archivo de la Diputación Provincial de Sevilla (ADPS) y Biblioteca Colombina (BC).

\section{DESARROLLO DEL TEMA}

El Hospital de las Cinco Llagas o también llamado de la Sangre se fundó en 1500 para atender a mujeres con enfermedades curables, accidentadas y heridas. No recibía a mujeres que tuviesen enfermedades venéreas que requiriesen de zarzaparrilla, unciones o sudores, ni las que tuviesen "llagas incurables", so pena de excomunión, porque ya existía un hospital en Sevilla para ello (Nepomuceno de Medina, 1966, 67-71). Antes de atender a las heridas tenían que estar confesadas y comulgadas, para ser admitidas en el hospital y el cirujano entraba con testigos a la sala de cirugía (Pérez Álvarez, 2013, 82). El cumplimiento de los preceptos era fundamental, pues este hospital sólo dependía de Roma, por bula dada por el papa Julio III en 1549, independiente de las autoridades civiles y religiosas, e incluso de la familia noble que lo fundó.

Durante cincuenta y nueve años estuvo ubicado intramuros de la ciudad de Sevilla hasta 
su traslado a un amplio edificio renacentista extramuros, en el arrabal de la Macarena, donde la enfermería femenina fue dividida en varias áreas separadas (Mena, 2010: 212 y 239).Una de ellas fue la cirugía que se llamó la Sala de San Juan. Esta área surgió como una necesidad natural en una ciudad cuyo apogeo económico había atraído cual imán a multitud de inmigrantes y las riñas y peleas con arma blanca eran comunes. De esta manera, desde la segunda mitad del siglo XVI y comienzos del XVII, la sección de cirugía de este hospital era una de las más demandadas, a pesar que ya existía en Sevilla un hospital cercano el San Hermenegildo o popularmente conocido como el Cardenal, fundado en 1453, dedicado a curar enfermos de ambos sexos al menos durante el siglo XV. Sin embargo, a mediados del siglo XVI, se había especializado como un hospital que atendía a heridos, e incluso se convirtió en un hospital para uso exclusivo de varones (González Díaz, 1997: 310-311). De esta manera, las mujeres no podían ocupar camas. Quizá por esa razón se abrió un área para heridas en el Hospital de la Sangre.

Poco a poco se fue configurando el personal de esta área, encargado de curar heridas violentas, fracturas, dislocaciones que requerían pronto socorro del cirujano, barbero, boticario,

madre enfermera en cirugía y sus doncellas. De esta pléyade de trabajadores, este trabajo de investigación se centrara en las mujeres que trabajaron en el área de cirugía del hospital

estudiado. Una sección que tuvo bastante acogida de enfermas en los siglos XVI y XVII, cayendo en desuso en el XVIII.

\section{Prolegómenos del área de cirugía del Hospital de la Sangre de Sevilla}

El primer reglamento del hospital, realizado en 1503, exigía que el cirujano que trabajase en el hospital fuese experto en su materia, de "buena consciencia y fama" y que fuese elegido por los tres patrones del hospital que eran los priores de los monasterios de Santa María de las Cuevas, San Jerónimo de
Buenavista y San Isidoro del Campo. El físico cirujano venía todos los días. Una de sus obligaciones era examinar las orinas de las enfermas (ADPS, Legajo 1, Constitución del Hospital de las Cinco Llagas de 1503) (Imagen 1). Sus órdenes eran cumplidas por la matrona que dirigía a las mujeres que trabajaban en el hospital. En 1506, el cirujano ganaba 1500 maravedíes y las dos cuidadoras que se encargaban de las enfermas y heridas recibían cada una 1400; sin embargo, en 1508, el cirujano recibió 2250 maravedíes, casi dos tercios más. En 1519 se volvieron a igualar los salarios del cirujano y las cuidadoras hasta 1548. En ese periodo, ambos cargos ganaban 2000 maravedíes anuales (Tabla $\mathrm{n}^{\circ} 1$ ).

\section{Imagen 1: Hospital las cinco llagas de Sevilla}

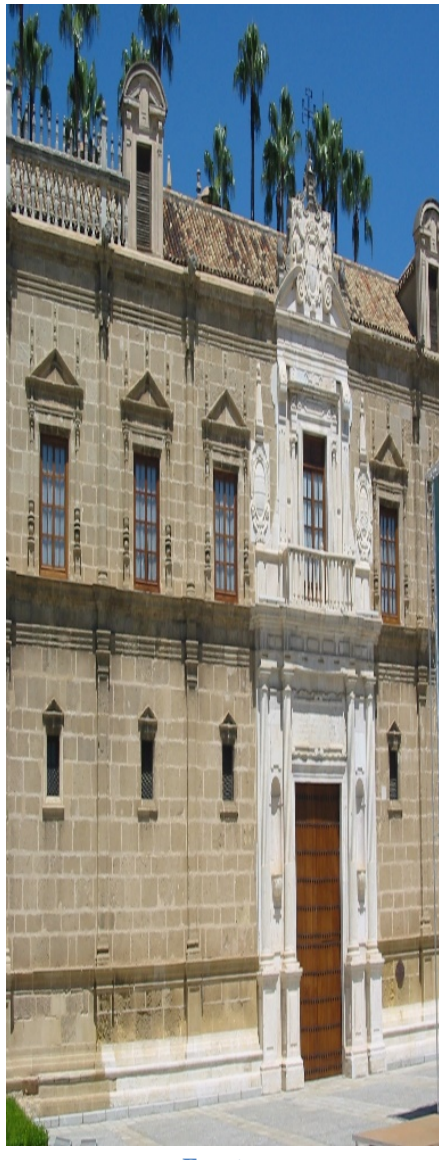

Fuente:

htps://es.wikipedia.org/wiki/Hospital_de_las_Cinco_Llagas\#/med ia/File:Parlamento_de_Andaluc\%C3\%ADa_(3508393367).jpgCr eative Commons. 


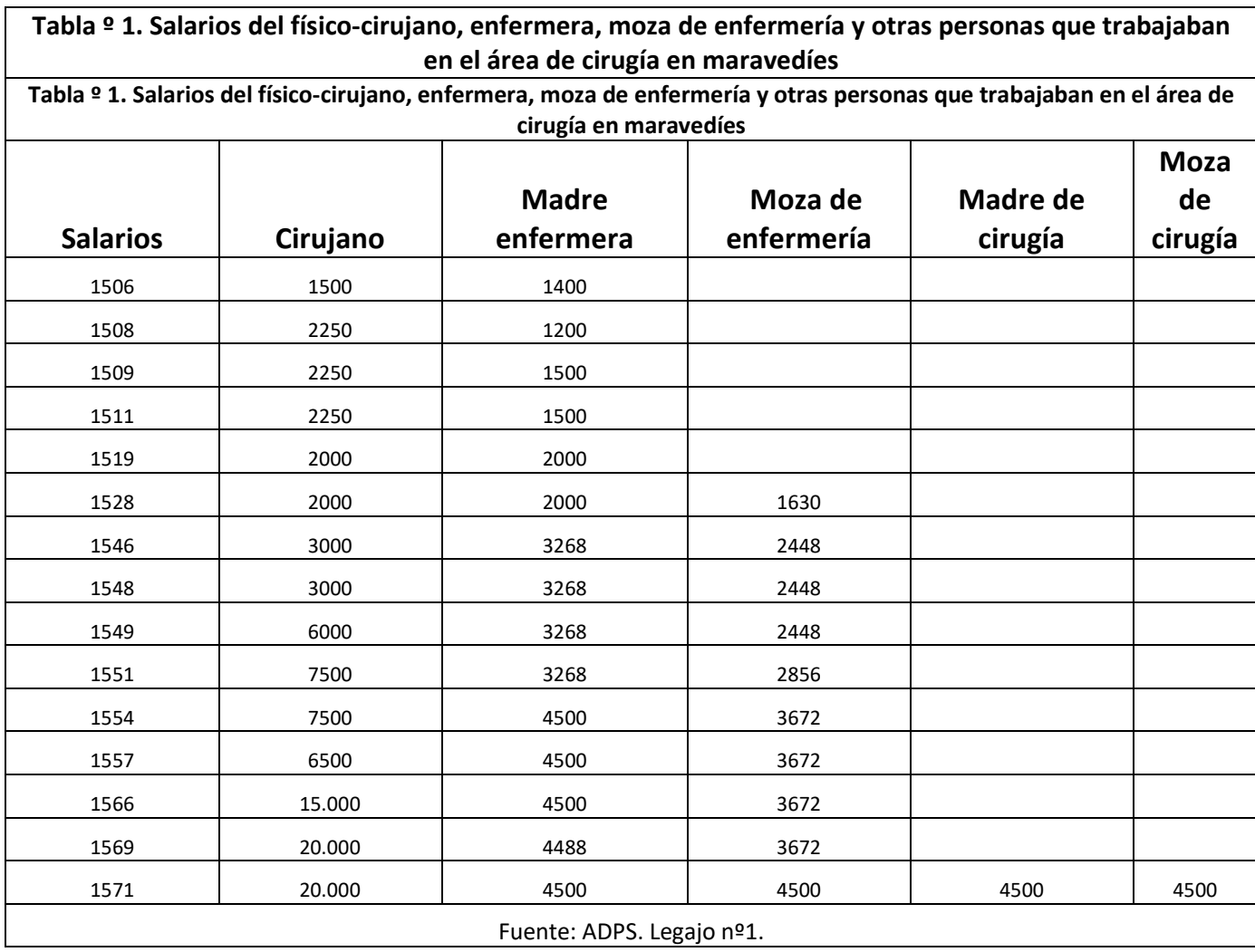

Sin embargo, se debe tener presente que las enfermeras trabajaban todo el día e incluso parte de la noche y dormían junto a las enfermas, mientras que el médico trabajaba sólo algunas horas al día, pero sus prescripciones e instrucciones determinaban las actividades diarias de todo trabajador del área de cirugía de este hospital. De esta manera, se pagaba igual la labor cuidadora femenina permanente "no académica” y el trabajo puntual sanitario "académico" masculino. Al menos en este hospital, se valoraban ambas características de modo análogo sin mediar diferencia, pues respondían a saberes y experiencias imprescindibles para el buen desempeño del hospital. Se ganaba según el esfuerzo ofrecido y demostrado. El quiebre de la similitud de salarios sucedió a partir del periodo de 1549 a 1570 cuando la cantidad recibida por el cirujano se duplicó y se mantuvo la de las cuidadoras. La diferencia salarial se agudizó veinte años más tarde cuando se produjo la uniformización del salario femenino en 1569 a 4488 maravedíes al año.

\section{La Madre Cirujana}

El antecedente más temprano de la madre cirujana fue la denominada "moza que ayuda a la madre de llaves” en 1561:

"La que busca paños para hilas. Se dieron a María Rodríguez que busca paños para cabezales y vendas para las heridas setenta y seis reales su salario dado de todo el presente año de 1561 de esta manera los ocho meses a seis reales y los cuatro meses a siete reales" (ADPS. Legajo 107. Libro de recibo y gastos, 1561, s/f). Dieron a la "moza que busca paños para hilas de enfermas de cirugía" o "que anda a demandar paños por las calles para la cirugía” 84 reales anuales a siete reales 
cada mes (Legajo107. Libro de recibo y gastos, 1562, s/f).

Esta mujer trabajaba fuera del hospital y su misión era buscar paños blancos o pedirlos a las personas caritativas para vendar a las heridas de cirugía del hospital, utilizando la tela o haciendo hilos de ella para otros requerimientos en el área. En la Edad Media, las intervenciones quirúrgicas eran vender las heridas e inmovilizar fracturas (D’Allaines, 1971: 30). El paño era materia prima esencial para vendar cabezas y curar heridas de las accidentadas que diariamente concurrían al hospital en busca de curación. La primera de éstas mujeres que reporta la documentación fue una joven beata, llamada María Fernández, intitulada "moza del cura” en 1563.

Estas mujeres eran popularmente reconocidas como sanadoras y solían pedir salarios a las autoridades municipales. Algunas de estas eran las beatas o mujeres cuyas vidas estaban dedicadas a Dios, y llevaban una vida activa de contacto con el exterior, dedicadas a las más duras y penosas labores asistenciales, en busca de la austeridad y la mortificación (Muñoz Fernández, 1994: 40-41), haciendo voto de castidad, pero no de pobreza ni de obediencia a ninguna orden religiosa (Perry, 1990: 25). Un ideal femenino a seguir entre las beatas del siglo XVI era Santa Mónica, la madre de San Agustín, o Santa Isabel, madre de San Juan Bautista, quienes además de consolar pobres y amortajar fallecidos, lavaban llagas sin mostrar asco alguno(Goldberg, 1974:203). Así, por ejemplo, María de la Cruz, beata descalza pobre, pidió limosna en la ciudad de Sevilla para un hospital durante la peste de 1599-1600. Otro ejemplo aún más conocido serían las beatas terciarias franciscanas Marta de Jesús y Beatriz de la Concepción quienes socorrían a pobres mujeres desamparadas, impedidas 0 incurables, asistiéndolas en su enfermedad y ayudándolas a bien morir, fundando el Hospital del Pozo Santo en 1666 (Perry, 2004: 63; Roda Peña, 2004: 21).

En 1566 trabajaba la "moza de cirugía", llamada Catalina, y en 1567, Anaya Salas. Una de sus tareas sería vendar a los heridos y llagados, empezando con la búsqueda de paños por la ciudad, que era una práctica más usual de lo que se cree entre las beatas. Por ejemplo, en la Valencia del siglo XVII, una beata buscaba trapos limpios para llevarlos al hospital y vendar a heridos y llagados. Por ejemplo, las veces que podía la beata Elena Martínez llevaba "trapos limpios, que con mucha diligencia buscaba entre sus amigas y entrabase a la cuadra del hospital que dicen la goleta, donde no ponen, sino a las mujeres llagadas de bubas..., pedían que les diese algunos trapos limpios, a que ella decía, que no los había de dar sino a aquellas, que tuvieran llagas” (Pons, 1991, 84). La tela era un material escaso durante todo el Antiguo Régimen español por lo que no se desperdiciaba nada de ella. Así, de la almoneda de ropa realizado en el Hospital de la Sangre que declaró María Fernández, natural de la montañas, muerta en el hospital en 1728, se trajo del corral de las Animas donde vivía una camisa hecha pedazos y remendada y muy vieja, destinada para trapos de la cirugía (ADPS. Legajo 263. Memorias testamentos almonedas de bienes de difuntos XVI -XVIII).

El área de cirugía del Hospital de las Cinco Llagas en su nueva ubicación en el arrabal de la Macarena extramuros de la ciudad fue donde surgió oficialmente el binomio enfermera de cirugía y su "hija", tal como eran llamadas las jóvenes aprendices que ingresaban al hospital a trabajar y a aprender un oficio a partir de 1571. La encargada de cirugía era la jefa que dirigía a las mujeres con las que trabajaba, entre las que estaban las doncellas o jóvenes que el hospital dotaba para matrimonio si trabajaban tres años consecutivos, establecido en este hospital. La jefa de esta área fue denominada "madre cirujana”, pues tal una madre debía cuidar a sus enfermas y enseñar a sus "hijas" o aprendices desde 1587. La madre debía estar presente al curarse las heridas para pasar al cirujano los hilos y las vendas, previamente preparados, así como los demás instrumentos quirúrgicos de la época, las sierras para cortar, las jeringuillas para contener hemorragias y los hierros para cauterizar. Así, la madre de cirugía debía tener limpios los instrumentos, llamados "hierros" que utilizaba el cirujano para cortar y quemar. También, debía aplicar las medicinas que el cirujano determinase, aprendiendo el uso de calmantes y ungüentos. El material instrumental se entregaba por el administrador a la madre cirujana, quien era responsable del mismo, 
dando fe de ello el notario apostólico del hospital.

La madre cirujana que permaneció por más tiempo en el cargo durante el siglo XVI fue Leonor Rodríguez de 1582 a 1589 y de 1592 a 1593. Otras madres de esta época fueron Velasco (1574), Elvira Sánchez (1576), Leonor de Escobar (1580), Leonor de Salvatierra (1585), Juana de Espinoza (1591), Barbola Cansino (1594 a 96) y Beatriz Guerra (159899). Desde 1559 a 1599, en su nuevo emplazamiento, el Hospital de las Cinco Llagas tuvo gran afluencia de heridas en el área de cirugía que obligó a designar tres mozas a la madre para que le ayudasen a atender a las 45 enfermas de cirugía de las 110 que había en la sala de enfermería en 1603. La madre cirujana permanecía siempre en la sala, incluso, dormía allí junto con sus ayudantes, mientras que el cirujano sólo venía puntualmente una vez al día o cuando se le requiriese para examinar a las heridas y permitir la admisión de nuevas pacientes.

En el siglo XVII, el área femenina del Hospital de la Sangre de Sevilla estaba ya configurado en varias secciones: enfermedades comunes, convalecientes, incurables, agonizantes y heridas. En este contexto, en 1608 , hubo un aumento de heridas y se necesitó de más ayudantes por lo que trabajaba en cirugía una beata, llamada María de Santa Ana que recibía 14 reales de vellón por mes (ADPS. Legajo 112. Libro de recibo y gasto de 1608, f.63 r). Sin embargo, la afluencia de enfermas a esta sección fue decayendo paulatinamente de tal manera que en la constitución de 1624 ya se consignaba sólo dos jóvenes para ayudar a la madre cirujana. En el siglo XVII, el hospital recibió a beatas y entre éstas destacó la madre cirujana María de San Joseph que trabajó en cirugía quince años consecutivos, de 1620 a 1635. Esta madre cirujana dejó junto a María de
Cárdenas una manda testamentaria en 1632 para dos misas cantadas perpetuas, realizadas durante las fiestas de la Encarnación y de la Concepción (ADPS. Legajo 177. Libros anuales de capellanías, misas, memorias del hospital de la Sangre 1626-1633). Ambas mujeres dejaron 100 ducados de principal al hospital y una renta anual de una casa que pagaba el convento de San Agustín calzados, extramuros de la ciudad de Sevilla. Esta manda se mantenía aún en 1824. Otra madre cirujana notable fue Marina Mora que trabajó de 1653 a 1658 y logró jubilarse, siendo la primera en esta área en obtenerlo, dándosele una limosna de 50 reales y una cama en el área de incurables en 1657. Otra madre cirujana jubilada fue Ana de Campos que trabajó de 1679 a 1693 y los patronos del hospital le dieron 12 reales como ayuda de costa en la junta del 19 de febrero de 1693.

En total 36 madres cirujanas trabajaron en el siglo XVII. Un 25\% trabajó sólo algunos meses, otro $25 \%$ trabajó un año, el $20 \%$ entre 1 a 3 años y el resto entre 3 a 12 años (Tabla n ${ }^{\circ} 2$ ). Las madres cirujanas ganaban 11 reales o un ducado al mes hasta 1602 cuando según la constitución de 1603 se les aumentó el salario a 14 reales mensuales.

En 1713, el hospital suspendió la plaza de cirujano y la cirugía se restringió a heridas que podían ser atendidas por la madre cirujana hasta 1724 cuando se volvió a contratar a un cirujano. En este lapso de tiempo se produjo una crisis económica en el hospital que obligó el cierre de varias enfermerías y reducción de personal, como las doncellas ayudantas de cirugía. En este periodo la madre cirujana María Gutiérrez asumió decisiones en cuanto a la curación de heridas ante la falta de cirujano, cargo que ejerció durante 27 años, de 1693 a 1720 (ADPS. Libro de recibos y pagos de 1721, f.102r). 


\begin{tabular}{|c|c|c|}
\hline \multicolumn{3}{|c|}{ Tablao 2. Madres de cirugía del Hospital de la Sangre del siglo XVII } \\
\hline Años & Nombre & Años de trabajo \\
\hline 1601 & María Cortés & 1 año \\
\hline 1602 & Catalina Guerra & 1 año \\
\hline 1603 & María García & 1 año \\
\hline 1604 & María Rodríguez & 1 año \\
\hline $1605-1608$ & Isabel Jiménez & 4 años \\
\hline 1609 & María de Esquivel & 1 año \\
\hline $1611-1612$ & $\begin{array}{l}\text { Juana Baptista que } \\
\text { había sido aprendiz en } 1600\end{array}$ & 2 años \\
\hline 1613 & Catalina García & 1 año \\
\hline $1613-1618$ & $\begin{array}{l}\text { Isabel Álvarez } \\
\text { que había sido aprendiz en } 1612\end{array}$ & 6 años \\
\hline $1619-1623$ & Inés Rodríguez & 5 años \\
\hline $1624-1635$ & $\begin{array}{l}\text { María de San Joseph murió ejerciendo } \\
\text { el cargo de madre cirujana }\end{array}$ & 12 años \\
\hline $1635-1636$ & $\begin{array}{l}\text { María Núñez, de madre del } \\
\text { tornillo a cirujana desde octubre de } 1635\end{array}$ & 1 año y 3 meses \\
\hline $1637-1642$ & Jerónima de los Reyes & 6 años \\
\hline 1643 & Catalina Clavero & 1 año \\
\hline $1644-1647$ & Andrea de la Trinidad & 4 años \\
\hline 1648 & Ana María & 1 año \\
\hline 1649 & No hubo. Año de la gran peste & 0 \\
\hline 1650 & Isabel de León & 1 año \\
\hline 1651 & Isabel de San Joseph & 1 año \\
\hline $1652-1659$ & $\begin{array}{l}\text { Marina Mora pasó de ropera } \\
\text { a cirujana, murió el } 15 \text { de enero de } 1659\end{array}$ & 7 y un mes \\
\hline 1659 & Ana Montero & 5 meses \\
\hline $1659-1660$ & $\begin{array}{l}\text { Ana de los Reyes murió el } \\
2 \text { de diciembre el } 1660\end{array}$ & 1 año y 5 meses \\
\hline $1661-1662$ & $\begin{array}{l}\text { Clara de Bocanegra hasta el } 15 \text { de julio de } \\
1662\end{array}$ & 1 año y 7 meses \\
\hline 1662 & $\begin{array}{l}\text { Juana de Torres hasta el } \\
22 \text { de septiembre del } 1662\end{array}$ & 2 meses \\
\hline 1662 & Beatriz Angulo & 3 meses \\
\hline $1663-1664$ & Juana de Sandoval & 2 años \\
\hline 1665 & Juana Duardo de junio de 1665 & 6 meses \\
\hline 1666 & Catalina de Mendoza & 6 meses \\
\hline 1666 & Bernarda del Castillo & 8 meses \\
\hline $1667-1668$ & María Fajardo & 2 años \\
\hline $1669-1670$ & Bernarda de San Francisco & 2 años \\
\hline 1671- 1676 & Bernarda de Velasco & 6 años \\
\hline 1676 & Ana de Campos & 2 meses \\
\hline $1677-1678$ & Francisca de Salcedo falleció & 1 año y 5 meses \\
\hline 1678 & María Aguilar falleció & 7 meses \\
\hline 1679 & Marina de los Reyes & 4 meses \\
\hline $1679-1693$ & $\begin{array}{l}\text { Ana de Campos hasta el } \\
24 \text { de junio de 1693. Jubilada. }\end{array}$ & 15 años \\
\hline $1693-1696$ & $\begin{array}{l}\text { María Gutiérrez ejerció la plaza } \\
\text { de cirujana desde } 25 \text { de junio } \\
\text { de } 1693 \text { hasta } 24 \text { de diciembre de } 1696 .\end{array}$ & 3 años y 5 meses \\
\hline 1697 & $\begin{array}{l}\text { María Páez de la Cadena que } \\
\text { fue madre portera entró como } \\
\text { cirujana desde } 01 \text { de enero de } \\
1697 \text { hasta el } 11 \text { de junio de } 1697 \text { que } \\
\text { murió }\end{array}$ & 6 meses \\
\hline 1697 más allá del siglo XVIII & $\begin{array}{l}\text { María Gutiérrez volvió a entrar } \\
\text { como madre cirujana desde el } 12-06 \text { de } \\
1697 .\end{array}$ & 4 años \\
\hline
\end{tabular}


Otra de las madres cirujanas más destacadas del hospital durante el siglo XVIII fue Catalina Sánchez que había sido previamente aprendiz con derecho a dote matrimonial. Fue precisamente en esta época en que disminuyeron drásticamente las enfermas de cirugía y coincidió con el punto álgido de la crisis económica castellana, así en 1730 no hubo ninguna enferma en cirugía (ADPS. Legajo 4B. Autos capitulares de 1716 a 1734, f.106r (1730)). Esta situación fue reflejada en la constitución de 1734, al destinarse sólo una ayudante a la madre de cirugía

De la madre cirujana. "Estuviese otra madre en el cuarto de San Juan, que es el de cirugía, y tenga para que le ayude, una doncella, la que fuere señalada por la madre mayor y le mandamos, que asista con toda caridad a las enfermas, y que ejecute los remedios, que dejare dispuestos el cirujano, teniendo prevenidas las vendas e hilos, y todo lo demás, que hubiere menester, y dispusiere el dicho cirujano, hallándose presente a la curación de mañana y tarde, pedirá la comida, y regalos, que necesitare para sus enfermas a la enfermera mayor”. (B.C. Constitución del Hospital de las Cinco Llagas de 1734. Fondo Gestoso, nº 110)

La sección de cirugía no tenía ya razón de ser, al disminuir la población sevillana y el Hospital de San Hermenegildo o del Cardenal podía cumplir con su cometido sin necesidad de otro hospital que lo secundase. Además no se debería olvidar que el Hospital de la Sangre no tenía como fin atender a heridas. De esta manera, en el siglo XVIII, se observa que el número de pacientes en cirugía fue reduciéndose por lo que sólo se consignaba una doncella para la ayuda de la madre cirujana de las tres que se daban en el siglo XVI y comienzos del XVII para la "asistencia de seis enfermas”. (ADPS. Legajo 4B. Libro de actas capitulares de 1688, f.6r (1688)). En el siglo XVIII hubo diecinueve madres de cirugía, dos de la cuales trabajaron de treinta y uno a veinte años que constituyó el 11\%. El 47\% trabajó de cuatro a ocho años y el $42 \%$, de algunos meses a dos años (Tabla $n^{\circ}$ 3).

\begin{tabular}{|c|c|c|}
\hline \multicolumn{3}{|c|}{ Tabla o3. Madres de cirugía del Hospital de la Sangre del siglo XVIII } \\
\hline & Nombre & Duración \\
\hline $1697-1720$ & María Gutiérrez & 20 años \\
\hline $1723-1726$ & Marcela de Medina & 4 años \\
\hline $1726-1730$ & Juana del Castillo Coronel & 5 años \\
\hline $1730-1731$ & Margarita de León & 1 año \\
\hline $1732-1739$ & Catalina Sánchez se jubiló en 1739. Murió el 24 de julio de 1742. & 4 años \\
\hline $1739-1747$ & $\begin{array}{l}\text { María de Flandes trabajó como madre cirujana hasta el } 15 \text { de marzo de } 1747 \text { que } \\
\text { pasó a ser madre de convalecientes. El } 13 \text { de mayo de } 1757 \text { se la jubiló. }\end{array}$ & 8 años \\
\hline 1747- 1750 & Teresa Moscoso de ropera a cirujana & 4 años \\
\hline $1750-1757$ & Catalina Arias de madre agonizante a cirujana, después pasó a ser madre enfermera. & 7 años \\
\hline $1758-1761$ & Eusebia Juanes de madre cocinera a cirujana & 4 años \\
\hline 1761 & Catalina Sánchez de 4 al 30 de junio de 1761 cuando murió. & 1 mes \\
\hline 1761 & María de Carmona & $1 \mathrm{mes}$ \\
\hline 1761 & Josefa González & 2 meses \\
\hline 1761 & Petronila Huelva & $\begin{array}{l}1 \text { mes } y \\
\text { medio }\end{array}$ \\
\hline $1762-1763$ & Rosa de Encinas & 1 año \\
\hline $1763-1764$ & María Márquez pasó de cirugía a enfermería & 1 año \\
\hline $1764-1770$ & Petronila de Huelva pasó del área de agonizante a cirugía & 5 años \\
\hline $1771-1776$ & Theresa de Otaudi & 6 años \\
\hline $1776-1777$ & Juana Ardila & 1 año \\
\hline $1778-1809$ & $\begin{array}{l}\text { Luisa de León fue reemplazada a veces por una suplente cuando trabajó en el área } \\
\text { de convalecientes. }\end{array}$ & 31 años \\
\hline
\end{tabular}




\section{Las doncellas aprendices de enfermería en el área de cirugía del hospital}

Las doncellas aprendices de esta área eran las que recibían mayor especialización de entre todas las jóvenes que ingresaban al hospital para aprender un oficio, pues tenían que conocer el instrumental utilizado por el cirujano de la época. Estas jóvenes eran conocidas en el hospital como las doncellas de dote del área de cirugía y como indica su nombre recibían un nombramiento para una dote de 50 ducados después de trabajar tres años consecutivos que la cobraban una vez que se casaban y velaban. Se les daba un plazo de tres años para hacerlo con una prórroga de unos más si lo solicitaban, sino perdían el nombramiento. También, se les pagaba un salario anual de 4488 maravedíes o 12 ducados, además de comida diaria.

Entre finales del XVI y comienzos del XVII, la sección de cirugía era una de las más demandadas del hospital, por lo que la madre de cirugía tenía a su cargo tres mozas; sin embargo, la afluencia de enfermas a esta sección fue decayendo paulatinamente. De tal manera que en la constitución de 1624, ya se consignaban dos doncellas de dote y en 1734 sólo había una (Tabla $n^{\circ} 4$ ). Y ya no se utilizaban "las sierras” de antaño, pues se había restringido la cirugía del hospital sólo a la cura de heridas leves y de alguna emergencia.

\begin{tabular}{|c|c|c|c|}
\hline \multicolumn{4}{|c|}{$\begin{array}{l}\text { Tabla nº }{ }^{4} \text {. Las mozas a cargo de la madre cirujana que trabajaban en la enfermería de cirugía } \\
\text { según la constitución de } 1603,1624,1734\end{array}$} \\
\hline Constitución & Lugar de trabajo & Actividades de la doncella de dote & $\begin{array}{l}\text { Número de } \\
\text { mozas }\end{array}$ \\
\hline 1603 & Cuarto de San Juan & Ayudar a la madre cirujana & 3 mozas \\
\hline 1624 & Cuarto de san Juan & $\begin{array}{l}\text { Ayudar a la madre cirujana en asistir a las } \\
\text { enfermas, ayudar a repartir la comida. }\end{array}$ & 2 hijas \\
\hline 1634 & Cuarto de San Juan & $\begin{array}{l}\text { Ayudar a la madre cirujana asistir a las } \\
\text { enfermas. } \\
\text { Ejecutar los remedios, que dejare dispuestos el } \\
\text { cirujano, teniendo prevenidas las vendas e hilos, } \\
\text { y todo lo demás, que hubiere menester. } \\
\text { Ayudar a repartir la comida. }\end{array}$ & 1 doncella \\
\hline
\end{tabular}

Estas doncellas de dote se encargaban de los servicios elementales en cirugía, como ayudar a las heridas en sus necesidades básicas (dar de comer, de beber y serviciales) y limpieza de la sala. Observaba la evolución de las heridas para avisar a la madre cirujana si ésta no se había percatado para hacérselo conocer al cirujano o al cura en caso de extremaunción. También aprendían el uso de las vendas, analgésicos, ungüentos y a tener limpios los instrumentos que utilizaba el cirujano, las sierras, cuchillos, tijeras, jeringuillas, pinzas y hierros. También estaba al tanto que estuviese dispuesto a la hora de las visitas del cirujano el batín, el agua con que se lavaba sus manos y la toalla para secarse. Las doncellas de cirugía dormían en la Sala de San Juan y se turnaban en la vigilia de las enfermas para poder estar pendientes de sus necesidades.

Era un área de alta especialización y las doncellas que ingresaban en ella estaban expuestas a observar cuadros desgarradores de dolor humano. Por ejemplo, en cirugía del hospital para evitar gangrenas se cortaban brazos y piernas. Existía una clara relación entre el área de cocina y cirugía, pues entre ambas áreas se dieron casos de intercambio de algunas doncellas de dote, como si una preparación a la de cirugía fuese la cocina. Incluso, algunas de estas doncellas de dote llegaron a ser madres de cirugía, como Juana Baptista, doncella en 1600 que pasó a ser madre de cirugía de 1611 a 1612 a madre cocinera en 1639. También, Isabel Álvarez, que al terminar su periodo como doncella de dote de cirugía en 1612, pasó a ser madre cirujana entre 1613 a 1618.

\section{De aprendiz a jefa del área de cirugía: la madre cirujana Catalina Sánchez}

Catalina Sánchez constituye el ejemplo más claro del ascenso de una niña de dote a jefa del área de cocina y cirugía. Esta mujer permaneció en el hospital toda su vida hasta su jubilación y muerte. Catalina nació en Zafra y sus padres eran Diego Martín y de María Freno. Entró a servir en una de las plazas de doncella de dote que ofrecía el hospital desde el 15 de noviembre 
de 1714 al 10 de julio de 1720, trabajando como doncella cocinera. "Catalina Sánchez doncella 8va desde el día 15 de noviembre de 1714 hasta el día 10 de Julio de 1720 que sirvió dicha plaza y pasó a la de madre cocinera” (ADPS. Legajo 187. Libro de pago de salarios 1707-1725, f.247 v y f. 248r). Le tocó trabajar en una época en la que no había jefa de cocina. La documentación indica que era muy devota y no solía comprar la ropa de las enfermas fallecidas, que se vendía en las almonedas del hospital, práctica usual en el Antiguo Régimen. Los libros salarios constatan que la joven tendía a no gastar y ahorrar su salario de tal manera que lo recibía integro.

Obtuvo dos dotes, una de 50 ducados y la otra de 30, que, con anuencia, de los patronos las donó como ayuda al costo del dorado del retablo de la Sra. de Belén del Hospital de la Sangre. Su presencia en la cocina fue tan necesaria que se le nombró en 1720 jefa de la cocina hasta 1732. En dicho lapso se enfermó en 1725 y fue reemplazada por una sustituta de cocinera llamada Isabel de Espinosa, sólo desde el 27 de junio al 31 de octubre de dicho año, a la que se pagó 22 maravedíes del sueldo de Catalina Sánchez. Después de ser la encargada de la cocina, los patronos la nombraron jefa del área de cirugía, madre cirujana, desde 1732 hasta 1739, cuando fue jubilada por acuerdo de los patronos con cama de incurable y una ayuda de 14 reales mensuales para vestidos y demás

\begin{tabular}{|c|c|c|c|}
\hline \multicolumn{4}{|c|}{$\begin{array}{l}\text { Tabla } 95 . \\
\text { Venta de los bienes de la madre Catalina Sánchez en almoneda del hospital }\end{array}$} \\
\hline \multicolumn{4}{|c|}{ e } \\
\hline Unas enaguas de calamaco & \multicolumn{2}{|c|}{ Unos vuelos de Bretaña } & Un pañuelo de seda \\
\hline $\begin{array}{l}\text { Un monillo o jubón de raso con puntilla de } \\
\text { plata }\end{array}$ & \multicolumn{2}{|c|}{ Un pañuelo de estopilla } & abanicos \\
\hline Delantal de tafetán con felpilla & \multicolumn{2}{|l|}{ Otro de lienzo } & Ligas \\
\hline Un monillo de pelo de camello & \multicolumn{2}{|c|}{ Un delantal de lienzo } & Mantilla blanca \\
\hline Una saya de pelo de camello & \multicolumn{2}{|c|}{ Una toalla de Bretaña } & Tres servilletas \\
\hline Cuatro camisas & \multicolumn{2}{|c|}{ Otra de crea } & Dos cuellos de encaje \\
\hline Dos tablas de manteles & \multicolumn{2}{|l|}{ Cintas de seda } & Unos guantes \\
\hline \multicolumn{4}{|l|}{ Alhajas de plata: } \\
\hline \multicolumn{2}{|c|}{$\begin{array}{l}\text { Dos rosarios engarzados en plata: uno de Jerusalén con su } \\
\text { cruz engarzada y el otro de Jesús María con cruz de plata. }\end{array}$} & \multicolumn{2}{|c|}{ Dos relicarios pequeños engarzados en plata. } \\
\hline \multicolumn{2}{|c|}{ Unos zarcillos de perlas negras con aretes de oro y piñitas. } & \multicolumn{2}{|c|}{$\begin{array}{l}\text { Una medalla de Santa Helena engarzada en } \\
\text { plata }\end{array}$} \\
\hline \multicolumn{2}{|c|}{ Una medallita de plata de Nuestra Señora de Guadalupe } & \multicolumn{2}{|c|}{ Una tumbaga de plata } \\
\hline \multicolumn{2}{|l|}{ Un petillito de plata sobredorada } & \multicolumn{2}{|c|}{ Una caja de plata } \\
\hline \multicolumn{2}{|c|}{$\begin{array}{l}\text { Tres agnus engarzados en plata, dos grandes con cristales y } \\
\text { otro pequeño sin ellos }\end{array}$} & \multicolumn{2}{|c|}{ Una cuchara de plata mediana } \\
\hline \multicolumn{2}{|l|}{ Una Santa Teresa engarzada en plata } & \multicolumn{2}{|c|}{ Un escarbadientes de plata } \\
\hline \multicolumn{4}{|l|}{ Dinero: } \\
\hline \multicolumn{2}{|l|}{20 reales en plata } & \multicolumn{2}{|c|}{300 reales de vellón } \\
\hline
\end{tabular}

menesteres (ADPS. Legajo 4B. Libro de autos capitulares de 1734 a 1763, f. 33 r.).

Su procedencia, nombre de padres y edad se conocen por su testamento elaborado por el cura Antonio de Santiago Moreno el 11 de julio de 1742(ADPS. Legajo 263. Memorias, testamentos, almonedas de bienes de difuntos, siglos XVI-XVIII, s/f). En este documento, pidió ser enterrada en una caja en la cripta de la iglesia del hospital. Mandó que se distribuyeran seis libras de chocolate a las enfermas del hospital al momento de su muerte para que la recordaran y rezaran por su alma. Lo que el hospital le debía de su salario se destinó en partes iguales para el culto del Cristo de la Sangre que estaba en la enfermería del hospital y para la Señora de Belén que estaba en la iglesia del hospital. La velación de su cuerpo se realizaría con dos acompañantes agregados a los estipulados por el hospital. Destinó todos sus bienes a misas por su alma a 3 reales cada una y nombró al hospital como administradora de todos sus bienes a ese fin. Se hizo venta de sus bienes en el hospital y el dinero obtenido se destinó a misas por su alma. En el inventario de sus objetos personales vendidos, uno puede constatar que tenía ropa de buena calidad e incluso joyas de oro y plata (Tabla $\mathrm{n}^{\circ} 5$ ). 


\section{Actividades diarias en la sala de San Juan}

Las actividades diarias en el área de cirugía o Sala de San Juan se fueron perfeccionando a medida que adquirían experiencia las personas que servían en el área. La primera acción del día era la misa, realizada en el altar que estaba en el crucero de las enfermerías, en verano a las $6 \mathrm{am}$. y en invierno a las 7 am. Acto seguido, el cirujano realizaba su ronda revisando a las heridas, para lo cual la madre cirujana tenía que tener preparada sobre la mesa una caja con todos los ungüentos y medicinas que el cirujano necesitara y con las vendas, paños e hilas necesarias, así como el brasero, que calentara los instrumentos y hierros que el cirujano utilizara. Las hilas eran hebras que se sacaban de un trapo de lienzo para curar las llagas y heridas. Las hilas eran embebidas en líquidos cicatrizantes con las que cubrían las heridas. Se usaban emplastos para confortar, hechos con estopa de lino o cáñamo, aguardiente, incienso, mirra y otras substancias. Según la constitución de 1624, el cirujano realizaba la visita a las enfermas en cama una vez al día en verano a las 8 am y en invierno a las 9 am y la constitución de 1734 indicaba dos visitas diarias: en verano a las 7:30 am y de 4 pm a 5 pm y en invierno a las 8:30 am y de 2 pm. a 3 pm.

El cirujano realizaba las visitas para examinar a las enfermas con la presencia de la madre cirujana y sus doncellas, a veces del boticario, sangrador y cura, con los que recorrían la sala de San Juan. Terminada la visita, se dirigía con la madre cirujana a revisar en un recibidor del hospital a las mujeres, que tenían heridas, apostemas, fracturas, dislocaciones y llagas frescas, cuyos tratamientos no requirieran de zarzaparrilla, unciones y sudores. Estas mujeres heridas esperaban ingresar en el área de cirugía. Si el cirujano necesitaba algo u observaba alguna falta lo debía avisar al administrador del hospital (ADPS. Constitución del Hospital de las Cinco Llagas de 1624). El cirujano atendía por dos horas a estas heridas en forma ambulatoria y las que eran admitidas a la sala de San Juan debían comulgar. También, el cirujano se acercaba al hospital toda vez que era necesitado en las emergencias y en las llamadas "visitas extraordinarias", por pedido del administrador.
Al marcharse el cirujano empezaba el trajín de la mañana para el cumplimiento de lo dispuesto por el cirujano. La madre cirujana y las doncellas atendían a las heridas con las indicaciones dadas por el cirujano, cambiando vendas y limpiándolas. Al mediodía, la madre cirujana recibía la comida de la madre mayor y lo distribuía con ayuda de sus doncellas, al terminar se preparaba a las enfermas para la siesta. A veces podría suceder una segunda visita del cirujano, en la que controlaba a las pacientes curadas en la mañana y a las nuevas ingresadas. Después se iniciaba el ajetreo de la tarde por el cumplimiento de lo dispuesto por el cirujano y el deber espiritual para terminar con la cena. Finalmente, la sala de San Juan donde la madre cirujana y sus doncellas dormían en la sala de enfermería se cerraba y estas mujeres se turnaban en la vigilia de las enfermas durante la noche.

\section{El cirujano del área de cirugía de San Juan del Hospital de la Sangre}

Prestigiosos cirujanos trabajaron en este hospital como Bartolomé Hidalgo Agüero que se especializó en el tratamiento de las heridas, causadas por arma blanca, al unir sus bordes para la cicatrización. Este cirujano empezó a trabajar en este hospital desde el 12 de enero de 1576 cuando ya estaba constituido el área de cirugía femenina hasta 1583, por lo que su presencia habría mejorado las técnicas empleadas para la curación de las heridas.

Los objetos que utilizaba el cirujano para curar a las heridas eran una jeringa pequeña de latón, una copa de hierro, una bacinilla de azófar y una serie de hierros que calentaban en un anafe u hornillo de hierro. Los hierros utilizados eran una sierra para cortar piernas o brazos, unas tijeras, unas pinzas, un cuchillo, catorce hierros de cauterio de fuego para quemar, otros hierros para otras curaciones. Se aplicaba dos clases de cauterios en el siglo XVI: El actual o real que era el hierro candente y el potencial o virtual que eran sustancias causticas. Es decir, el cauterio actual es aquel hecho por fuego y el cauterio potencial es el "fuego" producido por medicinas quemantes (Valverde López y Bautista Méndez ,1984: 22 y 158). También en la sala de San Juan se hacía uso de otro hierro que llamaban "speculum matrices", que era un dilatador vaginal utilizado en 
obstetricia. En la semana del 20 de octubre de 1638 se compró un speculum y se entregó a la madre Gerónima de los Reyes, madre cirujana, costó tres ducados (ADPS. Legajo 1 A. Libro inventario 1636, f. 289v- 290r). Este instrumento que fue usado desde la Antigüedad y que se siguió usando en la Edad Moderna desata una interrogante que me fue imposible contestar por carecer de más información que proporcionen las fuentes primarias consultadas (Hermosilla, 2001: 490 y 686). La interrogante sería si en este hospital femenino se realizaron inspecciones ginecológicas con el speculum para confirmar la virginidad o no de una mujer, para exploraciones vaginales o durante el parto. $\mathrm{Y}$ la duda se centra en quienes las realizaban. Se sabe que en la Antigüedad las hacían los cirujanos, pero no tan abiertamente en la Edad Media cristiana. En la Edad Moderna consta que los cirujanos recurrían a este instrumento más de lo que se cree en casos de inspección vaginal para detectar cáncer uterino, prolapsos e incluso para operar y dilatar en partos complicados. El "especulum matrices" se usaba desde la Antigüedad a la Edad Moderna. Aunque hubo avance médico en ginecología, pocas fueron las innovaciones en instrumentos ginecológicos. El cirujano Pierre Franco aconsejaba que todo cirujano debía tener un speculum vaginal para usarlo cuando fuese necesario. Los cirujanos Eucharius Rosslin en 1513 y Hans von Gersdorff en 1527 indicaban que el speculum servía para abrir anos para tratar hemorroides y para inspeccionar vaginas. El cirujano Rodrigo a Castro en un libro escrito en 1603 indicaba que utilizaba el speculum para examinar y operar los genitales femeninos. Guido Guidi, fallecido en 1569, escribió un texto de cirugía en el que indicaba que una cérvix enferma era detectada por el uso del speculum. Uno de los más interesantes tratados de Gynaecia fue la del cirujano Ambroise Paré (1510-1590) que usaba el speculum vaginal para remover úteros gangrenosos y cánceres de cuello uterino y en prolapsos (Vincent, 1990: 63-87). También, este instrumento pudo ser utilizado por las parteras, comadronas o simplemente las mujeres honestas que trabajaban en este hospital para realizar inspecciones ginecológicas urgentes. En cuanto a las parteras fueron aceptadas por obligación en este hospital como en otros, pues los médicos no comenzaron a intervenir directamente en los alumbramientos hasta mediados del siglo XVII. Las universidades sometidos a la Iglesia no podían avanzar en obstetricia más allá de lo debido, aunque algunos médicos lo hicieron en forma clandestina, muriendo en la hoguera, víctimas de la Inquisición, al pretender presenciar partos, como sucedió con el doctor Wertt en 1522, en Hamburgo(Eseverri, 1995: 63 y 166). Debido a estas razones y otras las comadronas estaban permitidas en todas las ciudades, existiendo ordenanzas y licencias exclusivas para ellas. En el siglo XVII se autorizó a los cirujanos para que puedan asistir a partos normales, actividad exclusiva hasta entonces de las matronas, en el Hospital Francés Hotel Dieu, extendiéndose la práctica en el resto de los países europeos. Según Ehrenreich, los médicos, barberos, cirujanos empezaron a invadir el último bastión de las sanadoras, la obstetricia, ya que las mujeres tenían prohibida la práctica de la cirugía. La obstetricia se convirtió en terreno masculino bastante rápido en Inglaterra y en Francia, pero el proceso fue más lento en Alemania y todavía más en los estados italianos, España y Europa oriental (Lindemann, 2001:130; Moral de Calatrava, 2013: 461-483; Hernández, 1996: 136; Ehrenreich, 1998: 20).

Hubo periodos en el que el cirujano del hospital podía vivir o no en el hospital. En 1571, el cirujano no lo hacía, por lo que no recibía ración de comida, pero se le entregaba toda la paja necesaria a su mula para que se desplazara rápidamente en caso de emergencia. En 1609, hubo un notable aumento de enfermas en cirugía, a tal punto, que el cirujano pidió aumento de su salario, lo que se le concedió.

"Petición que dio el cirujano de esta casa en que pide aumento de salario, mandaron que por haberse aumentado las enfermas de cirugía, se le aumentaran en cada un año y el dicho aumento, corra desde el primero de enero del año pasado de mil seiscientos $y$ ocho" (ADPS. Legajo 4A. Autos capitulares (1584 -1635), f.103, f.79r (1609))

El cirujano recibía sólo salario, mientras que un médico, en 1621, un salario de 160 ducados y ración de comida para él y su familia, consistente en una libra de carne, una libra de 
carnero o puerco, dos hogazas de pan negro y blanco, una libra de pescado salado, una libra de pescado fresco, doce arrobas de aceite cada año, veinticuatro arrobas de vino, agua de la alameda, hortaliza de la huerta del hospital, medicinas de la botica, veinticuatro fanegas de cebada, toda la paja necesaria para la mula y una casa (Legajo 4B. Libro de juntas patronales año 1623, f.43 r)

En 1610, aumentó la afluencia de heridas, por lo que el cirujano tenía la obligación de visitar a las enfermas dos veces al día. En invierno de ocho a nueve de la mañana y en verano de siete a ocho y por la tarde después de vísperas. En la tarde antes de visitar a las enfermas debía atender a las enfermas que estaban en la puerta, permitiendo que ocupasen cama sólo las que estuviesen permitidas. En la tarde comprobaba si las enfermeras habían hecho lo mandado. El cirujano también controlaba que el boticario del hospital tuviese bien provista la botica para la elaboración de las medicinas, en caso contrario daba parte de lo que faltase al administrador para poder tener todo lo necesario en las emergencias. En el mes de enero se realizaba la visita general encabezada por los patronos del hospital en el que debían estar presentes los cirujanos (ADPS. Lejago1. Constitución de 1606).

Sin embargo, empezó a disminuir la llegada de heridas al hospital desde 1623 y se redujo su salario a 80 ducados. Paulatinamente, el trabajo del cirujano aumentó, pues empezó a ejercer también de barbero, al punto que en 1638 los patronos le pidieron que viviese en el hospital, prohibiéndole que tuviese negocio externo en los llamados “cajones de cirugía” en la ciudad de Sevilla. Según este autor en 1616 se concluyó un cuarto que servía para albergar al médico, cirujano y barbero que trabajaban en el hospital (Morales, 1997: 91). En 1639, se limitó su trabajo a sólo cirugía, al crearse el puesto de sangrador en el hospital. Así, la presencia del cirujano fue perdiendo paulatinamente importancia al quitársele facultades y tareas. Pronto, los patrones decidieron que el cirujano no viviese en el hospital, aunque siguiese asistiendo en las mañanas a cirugía y visitando la botica dos veces al año en presencia del administrador. Después de la gran peste de 1649 en el que fallecieron 60.000 personas en Sevilla, el Hospital de la Sangre recibió pocas heridas y enfermas, pero fue aumentando su afluencia paulatinamente. Así, desde 1654 se empezó a pagar al cirujano 200 ducados y en 1682 hubo dos cirujanos en el hospital, los que alternaban sus obligaciones. El primero que era el cirujano propietario recibía 150 ducados al año y el segundo, que era el ayudante y tenía la sucesión de la plaza, 50 ducados. Los patronos acordaron que el salario del cirujano propietario, Gonzalo de Coria, fuese sólo 150 ducados anuales. Nombraron a Alonso Ramos como segundo cirujano para que en las ausencias y enfermedades de Gonzalo de Coria asistiese a la curación de las enfermas de cirugía, recibiendo por ello 50 ducados anuales. Y asimismo dijeron que para cuando llegara el caso de vacar dicha plaza de cirujano por muerte o cualquier accidente de Gonzalo de Coria, quedara nombrado en la propiedad de dicha plaza de cirujano Alonso Ramos a quien daban y dieron la futura sucesión (ADPS. Legajo 4B. Libro de juntas o actas capitulares, f. $177 \mathrm{v}$ (1682)). Incluso, había un sangrador, Juan Rodríguez, que recibía 114 ducados. El puesto de sangrador era muy importante, pues en aquel entonces se creía que la sangría era un alivio para muchos malestares. Pocos años después, en 1688, se despidió al segundo cirujano e incluso se le redujo el salario al que quedó por la mala situación económica que pasaba el hospital y Sevilla en general (ADPS. Legajo 4B. Libro de actas capitulares (1687-1715), f.5v (1688)). El hospital empezó a deber el salario al cirujano, acumulando deudas, a veces, de hasta 24 ducados, como sucedió en 1696. Desde 1698, el cirujano volvió a vivir en el hospital y recibió ración de comida, aumentando su salario de 100 a 150 ducados.

Otra vez, el hospital dejó de pagar todo el salario al cirujano en 1701. Incluso, en 1705 le disminuyeron 30 ducados, recibiendo sólo 120. Cantidad que sirvió para aumentar el salario del sangrador. El celo y tensión laboral entre el barbero y el cirujano eran evidentes. En la inundación de 1708 y la peste de 1709, el trabajo desempeñado por el cirujano incrementó y también su paga, recibiendo un exorbitante ingreso el año de 1712, al que se le sumaron todas las deudas que el hospital tenía con este profesional. El cirujano licenciado Gonzalo de 
Coria recibió los sueldos de 1709, 1710 y 1712 en uno, lo que sumó 1107 ducados.

El hospital practicaba la futura sucesión del cargo de cirujano, es decir, una plaza otorgada a una persona para asumirla cuando el cirujano titular muriese, cesara, abandonara el cargo por ir a las Indias.

"En los Virreinatos de Indias, durante la segunda mitad del XVIII, se incrementó la presencia de cirujanos españoles y extranjeros, motivado por la constante amenaza inglesa y con el fin de reforzar los contingentes militares que también se vieron incrementados en la América española. La actividad de estos cirujanos contribuyó a crear un clima más favorable para el ejercicio de la cirugía y de la disección anatómica, lo que motivó discrepancia con las instituciones universitarias novohispanas afianzadas en un saber más tradicional” (Cortes, 2003: 20).

Al morir el cirujano Gonzalo de Coria, los patrones del hospital determinaron suprimir la plaza porque, según el estatuto, no se debían curar heridas graves en el hospital, además, el área de enfermería trataba algunos casos de cirugía. El cirujano G. de Coria recibía 100 ducados y vivía en el hospital. Al morir, mandó traer 4000 escudos de Indias para donar parte al hospital, destinado a misas por su alma. Hizo un entierro importante (ADPS. Legajo 188. Libro de salarios 1766-1809). Por ahora no nombraban esta plaza, sino que la suprimían en atención a que según el estatuto, no se debían curar en este hospital casos de heridos graves sino simples, llagas frescas, descalabraduras, caídas u fracturas, o los casos de cirugía que resultaren de la sala de medicina de este hospital para lo cual no era necesario el empleo de cirujano mayormente cuando este hospital por sus atrasos y falta de renta no podía pagar este salario. Esta decisión lo tomaron los patronos del hospital (ADPS. Legajo 4B. Libro de actas capitulares (1687-1715), f.225 v (1713)).
De esta manera, en 1713 se suspendió la plaza de cirujano por los problemas económicos en el hospital que hacía imposible pagar su salario. No hubo más nombramientos en esta plaza. Pero se mantuvo al sangrador. Después de casi diez años, en 1722, se volvió a nombrar a un cirujano-sangrador aprobado por los exámenes dados en Sevilla para poder ejercer su oficio en la ciudad. Se trataba de Pedro Ramos Salcedo, ingresó con un salario de 100 ducados anuales, pero compraba objetos en las almonedas del hospital por lo que gastaba su salario, recibiendo menos. De 1731 a 1740 el cirujano continuó recibiendo 100 ducados, cuando al maestro sangrador le aumentaron 20 ducados que le quitaron del salario del cirujano, recibiendo desde entonces 80 ducados (ADPS. Legajo 187, Libro de salarios (1694-1765), f. $135 v)$. Esto se hacía porque el sangrador suplía al cirujano, en caso de ausencias o enfermedad y atendía a las heridas que llegaban a deshoras al hospital. En 1758 fue jubilado y le reemplazó José Domínguez. De 1759 a 1772, el salario de este cirujano fue 93 ducados. En este caso, los patronos impusieron a Domínguez, primero al sangrador Diego de Barrera y desde 1766 a Luis Moreira. El sangrador recibía 35 ducados más por asistir a las heridas cuando el cirujano no estaba. El cirujano trabajó hasta 1775 cuando falleció. El dinero que el hospital le debía fue entregado a su heredero, su hijo. Luis de Moreira asumió el cargo de cirujano y continuaba siendo sangrador, por lo que recibía dos salarios anuales que sumados eran 120 ducados desde 1776 a 1803. En 1809, el hospital tenía dos cirujanos, uno jubilado que era Luis de Moreira y otro propietario (ADPS. Legajo 188. Libro de salarios 1766-1809, f.127 r) $\left(\right.$ Tabla $\left.n^{\circ} 6\right)$.

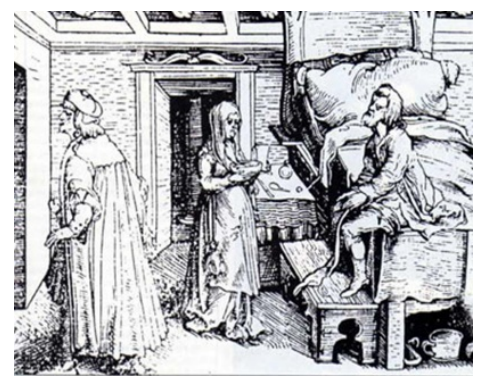




\begin{tabular}{|c|c|}
\hline \multicolumn{2}{|r|}{$\begin{array}{c}\qquad \text { Tabla n }^{\circ} 6 \\
\text { Relación de cirujanos que trabajaron en el Hospital de la Sangre }\end{array}$} \\
\hline $1557-1558$ & Médico y cirujano Martín López de la Cueva. \\
\hline $1559-1573$ & Licenciado Alfaro \\
\hline $1576-1582$ & Cirujano Bartolomé Hidalgo Agüero \\
\hline $1584-1599$ & Cirujano Francisco de Castro \\
\hline $1599-1623$ & Cirujano maestro Pedro Cachapero de Arévalo. \\
\hline $1623-1627$ & El maestro cirujano Pedro Sánchez Parraga \\
\hline 1628 & Cirujano Pedro Sánchez Parraga y cirujano Doctor Dionisio Vetus \\
\hline 1629 & Cirujano Doctor Dionisio Vetus y Francisco Fragoso \\
\hline $1630-1636$ & Cirujano Francisco Fragoso \\
\hline $1645-1673$ & Cirujano Andrés Osorio de Enciso \\
\hline 1674 & Cirujano José Valdez \\
\hline $1676-1682$ & Cirujano Joseph de Alderete \\
\hline $1682-1688$ & Cirujano titular Gonzalo de Coria. Cirujano segundo Alonso Ramos. \\
\hline $1689-1690$ & No hubo cirujano \\
\hline $1691-1713$ & Cirujano Gonzalo de Coria \\
\hline $1723-1759$ & Cirujano Pedro Ramos Salcedo \\
\hline $1759-1775$ & Cirujano José Domínguez \\
\hline $1776-1808$ & Cirujano Luis Moreira \\
\hline \multicolumn{2}{|c|}{$\begin{array}{l}\text { Fuente: ADPS. Libros de recibo y gastos. 1576-1587, leg. 108; Libros de recibo y gastos 1582-1589, leg. 109; } \\
\text { Recibo y gastos 1591-1595, leg. 110; Recibo y gastos 1596-1602, leg. 111; Recibo y gastos 1603-1609, leg. 112; } \\
\text { Recibo y gastos.1611-1617, leg. 113; Recibo y gastos 1618-1625, leg. 114; Recibo y gasto 1626-1632, leg.115; } \\
\text { Recibo y gastos. 1633-1641, leg. 116; Recibo y gastos 1639-1641, leg. 117; Recibo y gastos. 1645-1649, leg. 118; } \\
\text { Recibo y gastos. 1650-1655, leg. 119; Recibo y gastos 1656-1662, leg. 120; Recibo y gastos 1663-1669, leg. 121; } \\
\text { Recibo y gastos 1670-1676, leg. 122; Recibo y gastos 1677-1683, leg.123; Recibo y gasto 1684-1689, leg. 124; } \\
\text { Recibo y gastos 1691-1696, leg. 125; Recibo y gastos 1697-1703, leg. 126; Libro de salarios 1694-1765, legajo 187; } \\
\text { Libro de salarios 1766-1809, leg. 188. }\end{array}$} \\
\hline
\end{tabular}

\section{Descripción de la sala de cirugía o San Juan}

La cirugía no tuvo sala independiente hasta finales del siglo XVII. Todo el siglo XVI compartió sala con la enfermería. En 1603, las enfermas de cirugía ocupaban aún el fondo de la enfermería de San Pedro, donde se les curaba. El inventario de 1603 indica que había once cazos de sangrar de cobre, dieciséis cazos de untar de cobre, dos jeringas, siete candiles, dos ollas de cobre, una alcuza de cobre, tres calderetas de cobre para fregar cuando lavaban la enfermería, un brasero de hierro, una copa de cobre, dos anafes de hierro, un almirez de metal y un candelero de azófar (ADPS. Legajo 1A Inventario de 1603. s/f.).

El inventario de 1613 señala que la cirugía tenía un aparador con cuchillas, vasillos de estaño, una olla de cobre, una copa grande, dos candiles de garabato, un candelero de azófar y platos, uno de los cuales era para que el cirujano lavara sus manos. Las camas de la madre enfermera y sus doncellas estaban junto a las heridas para estar pendiente de sus necesidades. La cirugía fue perdiendo importancia con el tiempo y eso lo prueba el número de camas que tenía. Por ejemplo, en 1604 tenía cuarenta y siete camas, posteriormente, se redujo. En 1624, cuando aún la cirugía tenía fluidez de pacientes, ya se había trasladado en la Sala de San Juan que estaba ubicada en la parte superior de la cruz latina de enfermería. Según su primer inventario de 1636 como Sala de San Juan tenía cuarenta camas altas para las heridas y tres para la madre cirujana y dos doncellas. Las camas eran de banco y tablas con dos colchones, dos sábanas, dos almohadas, dos cobertores, uno de pelo y otro de paño. También había seis tarimas en la sala que se llamaban de "quadretas" con dos colchones, dos sábanas, dos almohadas, dos cobertores, uno de paño y otro de pelo y seis sábanas para remudar a estas enfermas. La cirugía tenía objetos para el culto divino, como 
un bufetillo con un cajón donde guardar los sacramentos y un paño que servía para cubrirlo. La habitación era iluminada con dos candeleros de azófar y dos candiles grandes con sus bolas. El agua hervida estaba en dos cazoletas de cobre, pero también había para otros usos dos cubetas de madera, un caldero, una paila, un arca grande y una copa. En una percha estaba un albornoz o batín que se ponía el cirujano cuando curaba y se lavaba en una fuente de latón y tenía dos toallas de lienzo para secarse.

En 1653, la sala de cirugía tenía veinticuatro camas y disminuyó a veintidós, dieciséis, siete y llegó a tener ninguna en 1721, pero pronto se incrementó el número de camas. En el inventario de 1726, ya no se encontraban varios de los instrumentos que utilizaban los cirujanos en comparación con el inventario de 1699, pues los cirujanos se fueron limitando a curar heridas y no a amputar piernas y otras "operaciones de alto riesgo”. Además, se redujo paulatinamente el número de doncellas ayudantes de tres a dos y uno que se constata en el inventario de 1699 y confirmado en la constitución de 1734. En el inventario de 1726 se encontraron en la sala de San Juan: dos velones de cuatro mecheros, dieciséis camas de tablas y bancos con pies de fierro con dos colchones, dos sábanas, dos almohadas, un cobertor y un paño para las enfermas y once tarimas. Había seis camas menos ocupadas por enfermos con relación al inventario de 1699. También estaba un banquillo y dos tablillas de entre camas. Se mantenían las dos camas de bancos y tablas de dos colchones cada uno con sábanas, almohadas, cobertores y paños para la madre cirujana y su doncella. También estaba un cofre viejo con su llave que tenía la madre mayor donde estaban todos los instrumentos y herramientas tocantes a cirugía. Dos arquitas pequeñas y muy viejas y sin llaves para hilas y trapos que servían de vendajes. Dos bufetillos, el uno para sacramentar con una cruz, una toalla y el otro para comer. En el inventario de 1726 ya no figuraba el instrumental quirúrgico de hierro que sí consta en su homologo de 1699: dos pares de tijeras grandes, una sierra de mano para piernas, dos jeringuillas una más pequeña que la otra para jeringar las llagas, un instrumento para cortar pechos y cuatro hierros de dar cauterios de fuego y otros cuatro para diferentes cosas. Llama la atención que todos estos instrumentos tocantes a cirugía estaban en un cofre viejo con su llave que tenía la madre mayor. Unos años más tarde, estas herramientas de cirugía ya no lo tendría la madre cirujana ni estarían en el cuarto de San Juan sino que finalmente se guardarían en el cuarto de la madre mayor, la responsable de todo el área femenina del hospital. También, estaba una fuente y un jarro pequeño de peltre y dos toallas para que el cirujano se lavara las manos, constando sólo el jarro en 1726, un arca vieja con su llave que tenía la madre cirujana en que se guardaban 24 camisas para las enfermas de esta sala. En cuanto al material de metal se encontraban: tres ollas de cobre y una hornilla para los cocimientos de cirugía, un perol de azófar, un velador de fierro y un candil de garabato, una recogedora de cobre para hilas, emplastos, una copa de cobre con pies de fierro, etc. (ADPS. Legajo 1A. Libro de inventario de bienes muebles del Hospital de la Sangre de Sevilla. 1699 y 1725 f. 124 r-v; 1726, f. 282 rv).

\section{CONCLUSIONES}

Este artículo es pionero en cuanto al tema del trabajo femenino en el cuidado de heridas en los hospitales del Antiguo Régimen castellano. La investigación llevó a detectar que en el Hospital de la Sangre se desarrolló un área de cirugía donde trabajaban cuidadoras, conformadas por la madre cirujana y sus ayudantes. Aunque el hospital recibió a heridas desde su fundación, la enfermería especializada en cirugía surgió en 1571 con la primera madre cirujana a la que se destinaron las primeras jóvenes que trabajaban para obtener una de las dotes matrimoniales de 50 ducados que ofrecía el hospital a partir de 1587.

Estas cuidadoras permanecían todo el día con las heridas, cumpliendo con las prescripciones dadas por el cirujano. Tenían establecido un régimen de trabajo a cumplir. Consta que cuando por algún motivo el cirujano descuidaba su trabajo, la madre cirujana tomaba decisiones mientras se restableciera la normalidad. El cirujano enseñaba cómo aplicar sus prescripciones a las cuidadoras y la responsable de que se cumplieran adecuadamente era la madre cirujana, teniendo como obligación mantener la sala y el equipamiento quirúrgico limpio $\mathrm{y}$ tener todo preparado para que el 
cirujano curase a las heridas, agua caliente, toallas, vendas, hornos, hierros calientes, etc. Es indudable el papel fundamental del cirujano en el desarrollo del área de cirugía de este hospital.

El área de cirugía de San Juan tuvo su máximo apogeo desde 1571 a 1649, año de la peste, desde cuando se redujo el ingreso de heridas y el número de ayudantas enviadas a la madre de cirugía. Pero en 1652 se incrementó el salario del cirujano al doble llegando a recibir tanto como el médico. A comienzos del siglo XVIII, otra gran peste e inundación, las de 1708 y 1709, aunados a la mala situación económica hizo desaparecer el área de cirugía para resurgir en 1724, pero con reducción de personal y prohibición de atender casos difíciles en cirugía. Sólo en contadas ocasiones se hacían disecciones cadavéricas de mujeres en este hospital previo permiso de los patronos y con la opinión favorable de varios médicos y cirujanos. En cuanto al "speculum matricis" que figuraba en el inventario de la sala de San Juan, pudo haber sido utilizado por el cirujano, la comadrona, lo que indicaría que los partos y revisiones ginecológicas pudieron haberse realizado en la sala de San Juan. La utilización de este aparato por el cirujano se controló menos en el siglo XVI y comienzos del XVII que en el XVIII, al prohibirse hacer cirugías complicadas en la Sala de San Juan. Esto se debía a que este hospital estaba bajo responsabilidad religiosa. Posteriores investigaciones al respecto podrían dar más luz al respecto.

En el Hospital de las Cinco Llagas de Sevilla se realizaban algunas disecciones cadavéricas de mujeres con permiso de los patronos del hospital, pero no se permitió la creación de una Escuela de Medicina hispalense para la formación de médicos y cirujanos en 1776, propuesta por el médico Sebastián Guerrero y Reina al rey Carlos III (Hermosilla, 2001:606; Chueca, 1989; 91). Mientras que el Hospital de San Hermenegildo, llamado El Cardenal, un hospital de varones, tenía una escuela de cirujanos desde comienzos del siglo XVII, incentivada por su propio patronato eclesiástico que era prácticamente el mismo que regía el de la Sangre, pues ambos compartían dos de sus patronos monásticos. La oposición de la Iglesia a la investigación quirúrgica de cuerpos femeninos salta a la vista, entablándose diferencias en la curación de enfermas y enfermos en el que saldrían perjudicadas las primeras.

\section{ARCHIVOS Y BIBLIOGRAFÍA}

\section{ARCHIVOS CONSULTADOS}

Archivo de la Diputación Provincial de Sevilla

Biblioteca Colombina

\section{BIBLIOGRAFÍA}

Beaujouan, G. (1965). La medicina y la cirugía en el monasterio de Guadalupe. Asclepio, XVII, 155-170.

Bouzakis A., et al. (2008). Design and manufacturing aspects of a vaginal speculum of antiquity, as investigated by computer tomographies. Journal of Archaeological Science 35, 633-642.

Chueca Goitia, F. (1989). Los Hospitales de Sevilla. Sevilla: Academia Sevillana de Buenas Letras.

Cortes Riveroll, J.G. R. (2003). De los cirujanos y sus procedimientos en el Real Hospital de San Pedro de la Puebla de los Ángeles. Clío, Nueva Época, 2(29), 17-25.

D’Allaines, C. (1971).Historia de la cirugía. Barcelona: Oikos-Tau.

Ehrenreich,B. (1988). Brujas, comadronas y enfermeras: historia de las sanadoras, Barcelona: Lasal.

Eseverri Chavarri, C. (1995). Historia de la enfermería española e hispanoamericana, Madrid: Editorial Universitas.

Goldberg, H. (1974). Jardín de nobles doncellas, fray Martin de Córdoba: a critical edition and study, Chapel Hill: Department of Romance Languages University of North Carolina.

González Díaz, A. M. (1997). Poder urbano y asistencia social: El Hospital de San Hermenegildo de Sevilla, (1453-1837). Sevilla: Diputación de Sevilla.

Hermosilla Molina, A. (2001). Cien años de medicina sevillana (La regia sociedad de medicina y demás ciencias de Sevilla, en el siglo XVIII).Sevilla: Ayuntamiento de Sevilla.

Hernández Martín, F. (1996). Historia de la enfermería en España: Desde la antigüedad hasta nuestros días. Madrid: Síntesis.

Herrera Dávila, J. (2010). El hospital del Cardenal de Sevilla y el Doctor Hidalgo de Agüero: Visión histórico sanitaria del Hospital 
de San Hermenegildo (1455-1837). Sevilla: Ediciones de la Fundación de Cultura Andaluza. Lindemann, M. (2001). Medicina y Sociedad en la Europa Moderna, 1500-1800, Madrid: Siglo XXI de España.

Mena, J. M. (2010). Historia de Sevilla. Barcelona: Plaza \& Janés Editores.

Muñoz Fernández, Á. (1994). Beatas y santas neo castellanas: ambivalencias de la religión y políticas correctoras del poder (siglo XIV-XVI). Madrid: Dirección General de la Mujer.

Moral de Calatrava, P. (2013). La «mujer cerrada»: La impotencia femenina en la Edad Media y el peritaje médico-legal de las parteras. Dynamis, 33 (2), 461-483.

Morales Martínez, A. J. (1997). La construcción del Hospital de las Cinco Llagas. Crónica de un monumento inacabado. El Parlamento de Andalucía. Sevilla: Parlamento de Andalucía, 77-97 y 229-234.

Nepomuceno de Medina y Torres, J. (1966). Ordenanzas del Hospital de San Cosme y San Damián (vulgo de las Bubas). Archivo hispalense: Revista histórica, literaria y artística, 44(135), 67-71.

Pérez Álvarez, M. J. (2013). El hospital de la Encarnación de Zamora en el siglo XVIII: Reglamentación y evolución asistencia. Revista de Historia Moderna, 31, 73-90

Perry, M.E. (1990). Gender and disorder in early modern Seville, New Jersey: Princeton University press.

Perry, M.E. (2004). Las mujeres y el trabajo curativo en Sevilla, siglos XVI y XVII., El
Trabajo de las mujeres, siglos XVI-XX. Madrid: Universidad Autónoma de Madrid, 57-70.

Pons Fuster, F. (1991). Mujeres y espiritualidad: las beatas valencianas del siglo XVII. Anales de la Universidad de Alicante, 10 (1), 71-96.

Valverde López, J., y Bautista Méndez, T. (1984). El códice de Cyrurgia de Teodorico de la Biblioteca Universitaria de Granada. Granada: Universidad D.L.

Vincent Ricci, J. (1990). The development of Gynaecological surgery and instruments, San Francisco (CA): Norman publishing. 